\title{
Regulation of Vascular Endothelial Growth Factor Expression by CAMP in Rat Aortic Smooth Muscle Cells
}

\author{
Maria E. Pueyo, ${ }^{1,2}$ Yan Chen, ${ }^{1}$ Gisela D'Angelo and J ean-Baptiste Michel \\ Faculté de Médecine Xavier Bichat, INSERM U460, 16, rue H. Huchard, 75018 Paris, France
}

\begin{abstract}
Vascular endothelial growth factor (VEGF) is an endothelial cell mitogen which stimulates angiogenesis. VEGF is regulated by multiple factors such as hypoxia, phorbol esters, and growth factors. However, data concerning the expression of VE GF in the different vascular cell types and its regulation by CAMP are not available. In the present study, we have investigated the effect of adenylate cyclase activation on VEGF MRNA expression in rat vascular cells in primary culture. Basal VEGF expression is greater in smooth muscle cells than in endothelial cells and fibroblasts. A 4-h treatment with forskolin $\left(10^{-5} \mathrm{M}\right)$ induced a 2-fold stimulation of VE GF mR NA expression in smooth muscle cells and fibroblasts, but, in contrast, did not affect VEGF expression in endothelial cells. In smooth muscle cells, a pharmacologically induced increase in intracellular cAMP levels using iloprost or isoprenaline led to a rise in VEGF MRNA expression comparable to that induced by forskolin. Adenosine, which increases cAMP levels in smooth muscle cells, also increases VEGF expression. Moreover, the 2.2-fold stimulation of VEGF expression by adenosine was enhanced following a cotreatment with cobalt chloride (a hypoxia miming agent). The observed additive effect (4.3-fold increase) suggests that these two factors, hypoxia and adenosine, regulate VEGF mRNA expression in smooth muscle cells by independent mechanisms. 1998 Academic Press
\end{abstract}

\section{INTRODUCTION}

Vascular endothelial growth factor (VEGF), a dimeric, heparin-binding glycoprotein, stimulates endothelial cell proliferation [1, 2]. VEGF binds to two highaffinity tyrosine kinase receptors selectively expressed in these cells [3, 4]. VE GF is produced by a great variety of normal and tumor cell types $[2,5]$. Analysis of the VEGF promoter revealed the existence of several potential binding sites for the transcription factors AP-1, AP-2, and SP1 [6]. Consistent with the presence of

\footnotetext{
${ }^{1}$ These authors equally contributed to this study.

${ }^{2}$ To whom correspondence and reprint requests should be addressed. Fax: 331448561 57. E-mail: pueyo@infobiogen.fr.
}

these enhancer elements, VEGF expression is upregulated in various cell lines by multiple factors, such as phorbol esters [6] and CAMP analogues [7], suggesting that this regulation is controlled by protein kinase $C$ (PKC) and cyclic AMP-dependent protein kinase (PKA)-mediating signal transduction pathways. VEGF expression has also been shown to be dramatically upregulated under hypoxic conditions [8, 9], by the transactivation of the hypoxia-inducible factor 1 (HIF 1 ) present on the promoter of the VEGF gene [10, 11]. Adenosine is a metabolite of adenine nucleotides [12], with ubiquitous biological effects [13]. The most important stimulus for the formation of adenosine appears to be an imbalance between $\mathrm{O}_{2}$ supply and $\mathrm{O}_{2}$ demand. This is observed in physiological situations of high metabolic activity, such as exercise, or in pathological situations, such as ischemia. Previous studies have shown that adenosine can directly stimulate angiogenesis by acting on endothelial cells [14]. We hypothesized that adenosine may indirectly stimulate angiogenesis by increasing VEGF production in smooth muscle cells. These cells express two types of adenosine receptors, $A_{1}$ and $A_{2}$, which are, respectively, negatively and positively coupled to adenylate cyclase [15].

Different studies have investigated the regulation of VEGF expression in vascular smooth muscle cells by cytokines [16] or growth factors [17]. In some studies, endothelial cells have also been found to express VEGF [18]. However, data concerning the expression of VEGF in the different vascular cell types and its regulation by CAMP are not available.

The purpose of this study was to compare VEGF expression and its regulation by CAMP in the different vascular cell types (endothelial, smooth muscle cells, and fibroblasts) of the same origin, the rat aorta. Our results showed that basal and forskolin-induced VEGF expressions are highest in smooth muscle cells (RSMC). Furthermore, in smooth muscle cells, VEGF mRNA levels rise in a dose-dependent manner in response to iloprost and isoprenaline. We also investigated the effect of adenosine on cAMP levels and VEGF expression in RSMC and we examined whether the regulation of VEGF mRNA expression by adenosine interacts with cobalt (an agent that mimics the effects of hypoxia). Our results show that adenosine increases CAMP levels 
and VEGF mRNA expression. Moreover, an additive effect of adenosine and cobalt was observed suggesting that these two physiologically interacting factors independently regulate VEGF mRNA expression in RSMC.

\section{MATERIALS AND METHODS}

Materials. Dulbecco's modified Eagle's medium (DMEM), N-2-hydroxyethyl pi perazine-N'-2-ethanesulfonic acid (Hepes), horse serum, and trypsin/EDTA were from Boehringer Mannheim (Germany). Penicillin, streptomycin, collagen, endothelial growth cell supplement (ECGS), adenosine, cobalt chloride, forskolin 3'-isobutyl-1methylxanthine (IBMX) and isoprenaline were from Sigma (St. Louis, MO). Collagenase was from Eurobio (France). Rat endothelial cell antibody was from Medac Diagnosika (Hamburg, Germany) and antibody against $\alpha$-actin was from Dako SA (Glostrup, Denmark). $\left[\gamma^{-33} \mathrm{P}\right]$ Adenosine $5^{\prime}$-triphosphate was from Isotopchim (France). Primers for PCR amplification were synthesized by Eurogentec (Belgium). TriZol isolation kit, Moloney murine leukemia virus reverse transcriptase, and Taq polymerase were from Life Technologies, Inc. Iloprost was from Schering (France). CDNA of rat VEGF ${ }_{164}$ was a gift from A. Ladoux (CNRS, UPR 411, France).

Cell culture processing. Endothelial cells (RAEC), smooth muscle cells (RSMC), and fibroblasts (RAF) were isolated from rat aorta as previously described [19]. Briefly, thoracic aortae were excised and rinsed. The adventitia was mechanically dissociated from the media plus endothelium. Each part was sliced into fine rings and incubated in DMEM containing collagenase $(1248 \mathrm{UI} / \mathrm{ml})$ for $40 \mathrm{~min}$ at $37^{\circ} \mathrm{C}$. The rings were flushed and filtered to dislodge the cells. Cell suspensions were centrifuged, resuspended in cultured medium, and plated in a plastic flask. For endothelial cells, the flask was coated with rat fibronectin and cells incubated for $40 \mathrm{~min}$ at $37^{\circ} \mathrm{C}$. This short period allowed only endothelial cells to adhere. RSMC were isolated by placing the aortic rings in a second enzymatic bath containing collagenase $(1248 \mathrm{UI} / \mathrm{ml})$ and elastase $(17.5 \mathrm{UI} / \mathrm{ml})$ for $60 \mathrm{~min}$ at $37^{\circ} \mathrm{C}$. The cell suspension was centrifuged, resuspended in culture medium, and plated out in plastic flasks coated with $0.1 \%$ collagen. Confluent RAEC were detached using trypsin/EDTA and propagated in DMEM supplemented with $15 \%$ horse serum, $5 \%$ FCS, $75 \mu \mathrm{g} / \mathrm{ml}$ ECGS, 20 $\mathrm{mM}$ Hepes, $2 \mathrm{mM}$ glutamine, $50 \mathrm{UI} / \mathrm{ml}$ penicillin, $50 \mu \mathrm{g} / \mathrm{ml}$ streptomycin, and $0.125 \mu \mathrm{g}$ amphotericin B. RSMC and fibroblasts were cultured in DMEM supplemented with $10 \%$ FCS. Cells from passages 2- 3 were used in these studies.

The purity of cell preparations was verified by immunostaining with RECA, a specific rat endothelial cell antibody [20], and with a monoclonal antibody for smooth muscle $\alpha$-actin.

Before treatment with different substances, confluent cells were serum deprived for $24 \mathrm{~h}$. Cells were then incubated for $4 \mathrm{~h}$ with concentrations of the various agents as indicated in the text.

RNA isolation and analysis by Northern blot. Total RNA was isolated from confluent cultures of RAEC, RSMC, and RAF according to the assay conditions with Trizol. For Northern Blot analysis, 20 $\mu \mathrm{g}$ of total RNA was separated in a $1 \%$ agarose gel. RNA was transferred by capillarity onto a Hybond-N membrane and cross-linked by ultraviolet irradiation. The agarose gel-purified cDNA probe for VEGF $_{164}$ (350 bp, corresponding to nucleotides 168-517) was labeled with $\left[\alpha-{ }^{32} \mathrm{P}\right] \mathrm{dCTP}$ and purified using Nick columns. Blots were hybridized overnight at $42^{\circ} \mathrm{C}$, in $50 \%$ deionized formamide, $5 \times \mathrm{SSC}$ ( $1 \times$ SSC, $0.15 \mathrm{M} \mathrm{NaCl}, 0.015 \mathrm{M}$ sodium citrate), $1 \times$ Denhardt's solution, $50 \mathrm{mM}$ sodium phosphate ( $\mathrm{pH} 6.5$ ), $0.1 \%$ sodium dodecyl sulfate (SDS), and $250 \mu \mathrm{g} / \mathrm{ml}$ denatured salmon sperm DNA. The blots were then washed twice with $0.5 \times$ SSC and $0.1 \%$ SDS at room temperature for $15 \mathrm{~min}$ and with $0.1 \times \mathrm{SSC}$ and $0.1 \%$ SDS at $42^{\circ} \mathrm{C}$ for 10 min and finally exposed to Hyperfilm-MP film at $-80^{\circ} \mathrm{C}$. Blots were rehybridized with a probe for the $28 \mathrm{~S}$, to compare the RNA loading in each lane.
A

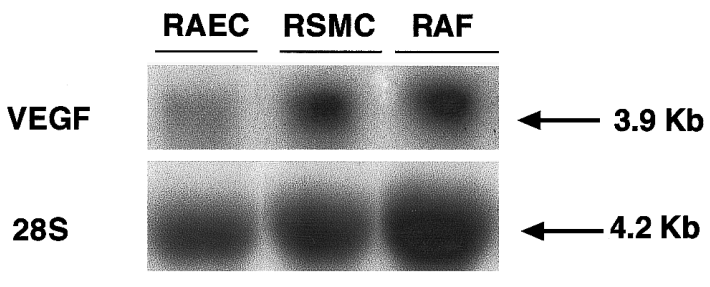

B

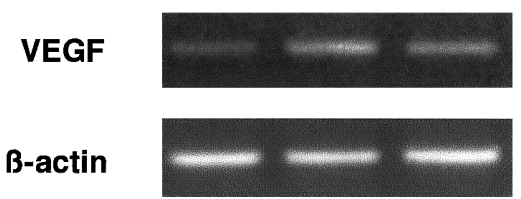

FIG. 1. VEGF mRNA expression in the three cell types of rat aorta. (A) Evaluation by Northern blot analysis. Total cell RNA (20 $\mu \mathrm{g}$ ) obtained from confluent RAEC, RSMC, and RAF were el ectrophoresed, blotted, and hybridized with the rat VEGF CDNA probe. Blots were rehybridized with the $28 \mathrm{~S}$ probe, to compare RNA loading in each lane. (B) Evaluation by RT-PCR assays. Total RNA was reverse transcribed and amplified using specific oligonucleotides for VEGF and for $\beta$-actin. PCR products were separated on ethidium bromidestained agarose gel.

Comparative RT-PCR. After treatment with different compounds, total RNA was isolated according to the assay conditions with Trizol. For the reverse transcription stage, single-stranded cDNA was synthesized from $400 \mathrm{ng}$ of total RNA in the presence of Moloney murine leukemia virus reverse transcriptase and the oligo(dT) primers.

For PCR, oligo primers were chosen from homologous parts of the coding region of the rat VEGF gene: the sense primer was $5^{\prime}-\mathrm{CTG}$ GAC CCT GGC TTT ACT GCT-3' and the antisense primer was 5'GCA CTC CAG GGC TTC ATC ATT-3'. Double-stranded CDNAs were synthesized and amplified using $1.25 \mathrm{U}$ Taq polymerase, 20 $\mathrm{mM}$ Tris- $\mathrm{HCl}$ (pH 8.0), $50 \mathrm{mM} \mathrm{KCl}, 0.2 \mathrm{mM}$ of dNTP, 20 pmol of each primers of VEGF, $1.5 \mathrm{mM}$ of $\mathrm{MgCl}_{2}, 4 \times 10^{5} \mathrm{cpm}$ of ${ }^{33} \mathrm{P}$-endlabeled primer in a $25-\mu$ l reaction final volume. The amplification was carried out in a DNA thermal cycler 480 (Perkin-EImer) at 95, 64 , and $72^{\circ} \mathrm{C}$ for $30 \mathrm{~s}, 1 \mathrm{~min}$, and $1 \mathrm{~min}$, respectively, for 29 cycles. In order to permit semiquantitative analysis, RT-PCR of the housekeeping gene $\beta$-actin was used at 95,64 , and $72^{\circ} \mathrm{C}$ for $30 \mathrm{~s}, 1$ $\mathrm{min}$, and $1 \mathrm{~min}$, respectively, for 19 cycles. The primers for the rat $\beta$-actin were $5^{\prime}$ TGG AAT CCT GTG GCA TCC ATG AAA C 3' for the antisense primer and 5' TAA AAC GCA GCT CAG TAA CAG TCC G 3' for the sense primer.

PCR fragments were analyzed by $8 \%$ polyacrylamide gel electrophoresis and visualized by ethidium bromide staining. Bands were cut out, dissolved in periodic acid ( $25 \mathrm{mM})$, and counted using a RackBeta liquid scintillation counter.

Statistics. Values are expressed as means \pm SEM. Effects of stimulation on VEGF expression were compared using a two-way ANOVA.

\section{RESULTS}

Expression of basal and forskolin-stimulated VEGF mRNA expression in rat vascular cells. Northern blot 
was performed with total RNA isolated from the RAEC, RSMC, and RAF. At the basal level, VEGF is differentially expressed in the three types of rat aortic cells: RAEC, RSMC, and RAF (Fig. 1A). The 3.9-kb VEGF transcript detected by Northern blot analysis was greater in RSMC and RAF than in RAEC. These results were confirmed by RT-PCR assays (Fig. 1B). VEGF expression in RAEC was, respectively, five and three times lower than that in RSMC and RAF.

We investigated whether forskolin, an adenylate cyclase activator, was capable of enhancing VEGF mRNA expression in rat aortic cells. Figure 2 shows that a 4-h treatment with forskolin $\left(10^{-5} \mathrm{M}\right)$, an adenylate cyclase activator, induced a twofold increase in basal VEGF mRNA expression in RSMC and RAF . In contrast, forskolin had no effect in RAEC.

Effect of high levels of CAMP on VEGF mRNA expression. To further investigate the effect of an increase in intracellular CAMP on VEGF mRNA expression, RSMC were treated with different concentrations of adenylate cyclase activators. Figure 3 shows that a 4-h treatment with forskolin, iloprost, or isoprenaline enhanced VEGF mRNA expression in RSMC in a dose-dependent manner.

Effect of adenosine on CAMP levels and VEGF expression in RSMC. In order to determine the effect of adenosine on RSMC, CAMP intracellular levels were evaluated by radioimmunoassay. A 10-min treatment with adenosine dose dependently increased CAMP levels $(r=0.93 ; P<0.0001)$. The highest concentration used $\left(10^{-4} \mathrm{M}\right)$ induced a threefold elevation in CAMP levels (Fig. 4A). A 10-min incubation with $0.1 \mathrm{mM}$

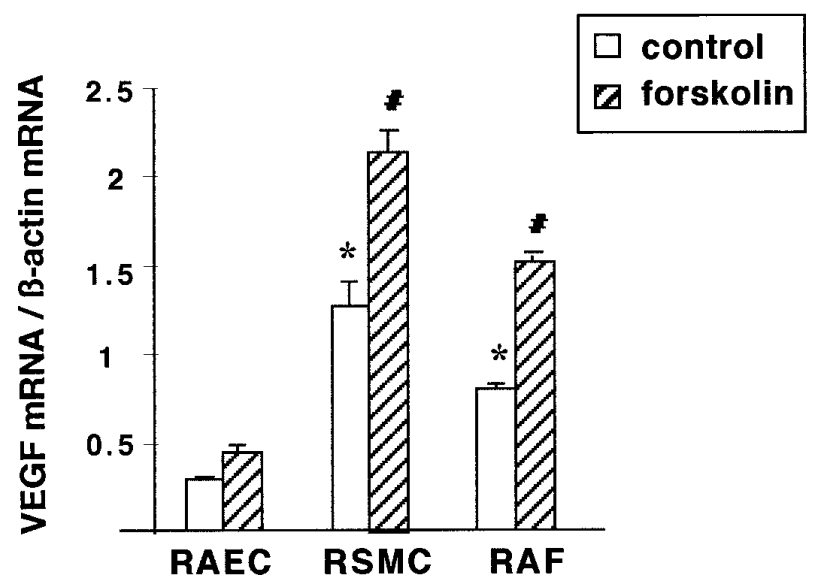

FIG. 2. Effect of forskolin on VEGF expression in rat aortic cells. Total RNA from cells untreated or treated for $4 \mathrm{~h}$ with $10^{-5} \mathrm{M}$ forskolin was reverse transcripted and amplified using specific oligonucleotides for VEGF and for $\beta$-actin. Quantification of amplified fragments was determined by counting the incorporated radioactivity. Results are expressed as the ratio of VEGF mRNA relative to the $\beta$ actin mRNA levels. Results are means \pm SEM of threeto six independent experiments. *P $<0.05$ compared to RAEC. \#P $<0.05$ compared to untreated cells.

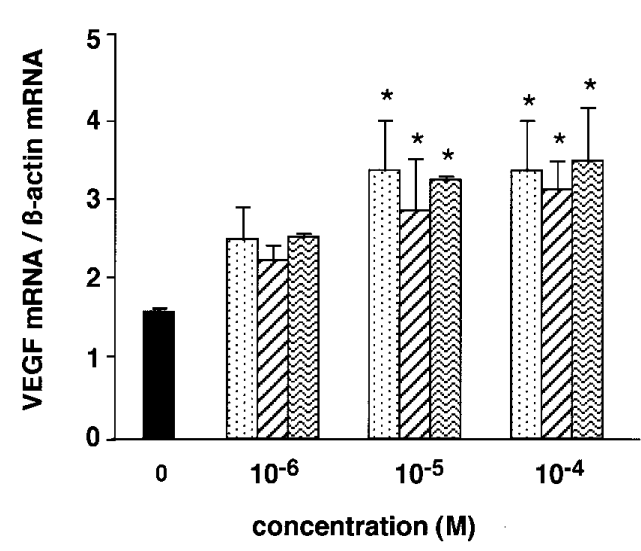

basal forskolin 乙 iloprost isoprenaline

FIG. 3. VEGF expression in response to different CAMP-elevating agents in RSMC. Cells were treated for $4 \mathrm{~h}$ with increasing concentrations of forskolin, iloprost, and isoprenaline as indicated. Total RNA was prepared, reverse transcribed, and amplified as described under Materials and Methods. Quantification of amplified fragments was determined by counting the incorporated radioactivity. Results are expressed as the ratio of VEGF MRNA relative to the $\beta$-actin mRNA levels. Results are means \pm SEM of three to five independent experiments. $* \mathrm{P}<0.05$ compared to control.

IBMX, a phosphodiesterase inhibitor, caused a twofold increase in intracellular CAMP concentration. The cotreatment with the two lower doses of adenosine was not significantly different from that induced by IBMX alone. However, at $10^{-4} \mathrm{M}$ adenosine the enhancement of CAMP accumulation was potentiated. The positive effect of adenosine on CAMP led us to investigate the effect of adenosine on VEGF mRNA expression. Figure $4 \mathrm{~B}$ shows that $10^{-4} \mathrm{M}$ adenosine significantly stimulates VEGF mRNA levels. The adenosine concentration required to stimulate adenosine-induced CAMP accumulation (Fig. 4A) was similar to that which enhanced adenosine-induced VEGF mRNA expression. Our results show, for the first time, that an increase in CAMP via stimulation by adenosine leads to the upregulation of VEGF expression in RSMC.

Interaction of adenosine and cobalt on VEGF mRNA expression. In order to explore a possible interaction between adenosine and hypoxia on VEGF mRNA expression, RSMC cells were treated with adenosine, $\mathrm{CoCl}_{2}$ (to mimic hypoxic conditions), or both factors simultaneously. A 4-h treatment of RSMC with $10^{-5} \mathrm{M}$ $\mathrm{CoCl}_{2}$ and $10^{-4} \mathrm{M}$ adenosine, induced, respectively, a 2.4- and 1.6-fold increase of VEGF expression over basal values (Fig. 5). The actions of adenosine and $\mathrm{CoCl}_{2}$ were additive (4.2-fold). These results suggest that in RSMC, the upregulation of VEGF mRNA expression can be mediated by two independent mechanisms.

\section{DISCUSSION}

The current study demonstrated a differential expression of VEGF in rat aortic cells: VEGF is expressed 
in RAEC, but the higher expression of VEGF in RAF and in RSMC indicate that VEGF may act predominantly as a paracrine factor in the vascular wall. In addition we demonstrated that forskolin, an adenylate cyclase activator, has a differential regulatory effect on VEGF mRNA expression in these cells. We found that the basal VEGF mRNA expression in RSMC and RAF was doubled by forskolin treatment. In contrast, no effect of forskolin was observed in RAEC, suggesting that high levels of CAMP do not affect VEGF mRNA expression in this cell type. A slight inhibitory effect of forskol in was recently reported on VEGF expression in pig cer ebral microvascular endothelial cells [21]. Taken

A

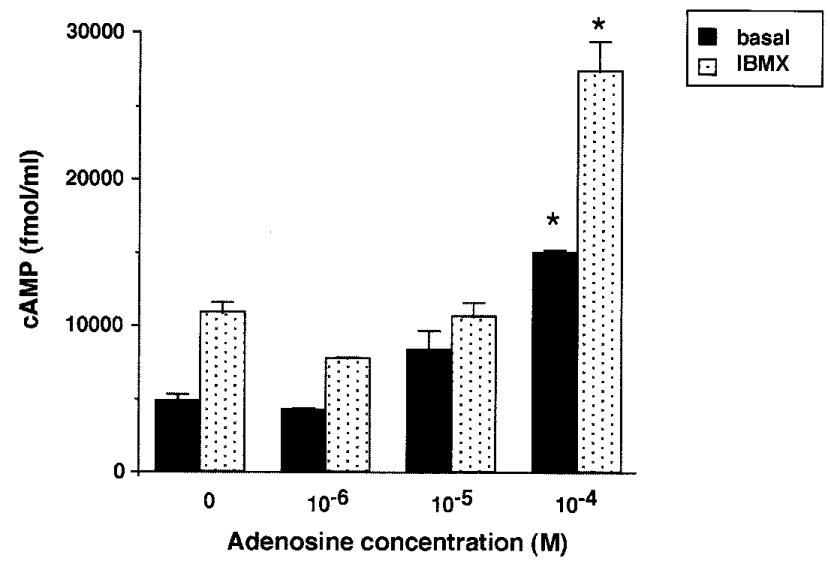

B

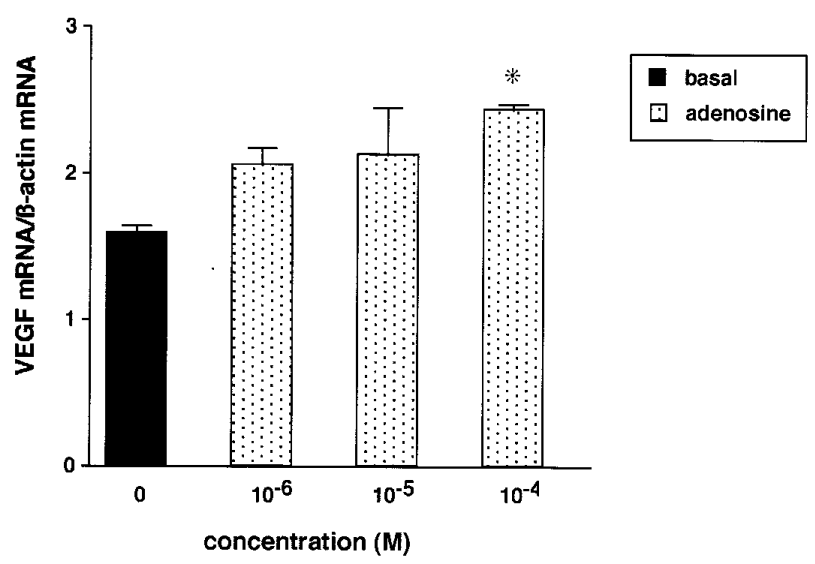

FIG. 4. Effect of adenosine on intracellular CAMP levels and on VEGF expression in RSMC. (A) Cells were cultured with increasing concentrations of adenosine for $10 \mathrm{~min}$ in the presence or absence of IBMX $(0.1 \mathrm{mM})$. Levels of CAMP were determined by radioimmunoassay. Values represent the mean \pm SEM of three independent experiments. ${ }^{* P}<0.05$ compared to control. (B) Total RNA from cells treated for $4 \mathrm{~h}$ with increasing concentrations of adenosine was prepared, reverse transcribed, and amplified as above. Quantification of amplified fragments was determined by counting the incorporated radioactivity. Results are expressed as the ratio of VEGF mRNA relative to the $\beta$-actin mRNA levels. Results are means \pm SEM of three independent experiments. $* \mathrm{P}<0.05$ compared to control.

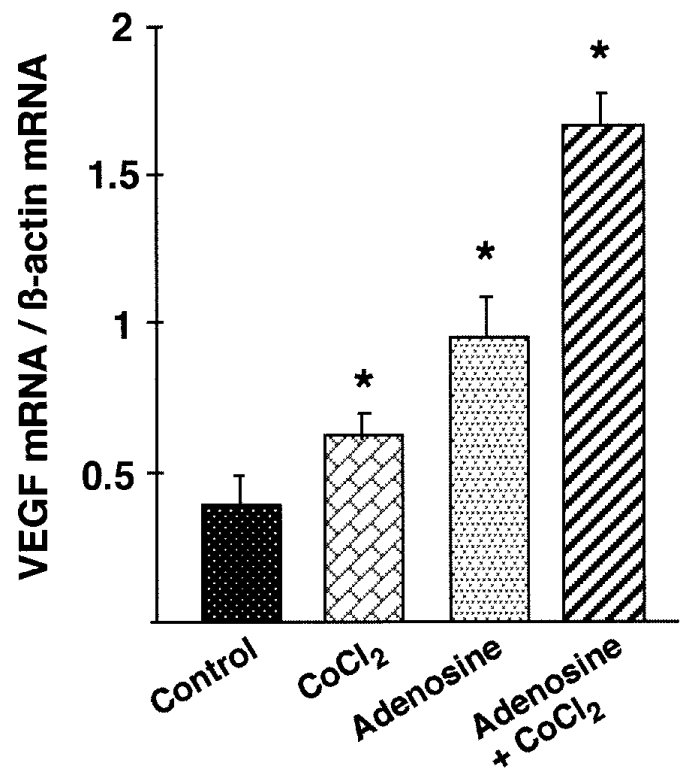

FIG. 5. Effect of $\mathrm{CoCl}_{2}$ and adenosine on VEGF expression in RSMC. Cells were untreated or treated for $4 \mathrm{~h}$ with $10^{-4} \mathrm{M}$ adenosine, $10^{-5} \mathrm{M} \mathrm{CoCl}_{2}$, or both factors simultaneously. Results are means $\pm \mathrm{SEM}$ of three independent experiments. ${ }^{*} \mathrm{P}<0.05$ compared to control.

together, these results suggest that the VEGF mRNA expression in RSMC and RAF is increased by forskolinactivated adenylate cyclase and they confirm that, in endothelial cells, high levels of CAMP are not responsible for the induction of VEGF expression.

We have shown that in the vascular wall, smooth muscle cells are the main source of VEGF and that its expression is upregulated by CAMP-elevating agents, such as iloprost or isoprenaline, which act via different mechanisms. Forskolin directly activates adenylate cyclase, whereas iloprost and isoprenaline bind to receptors positively coupled to adenylate cyclase. Our results are consistent with previous observations showing a positive effect of forskolin and $\mathrm{PGE}_{2}$ in other cell types [7, 21, 22]. However, Harada et al. [23] hypothesized that the $\mathrm{PGE}_{2}$-induced expression of VEGF in osteoblasts is mediated not only by the rise in CAMP levels, but also by other second messengers. Conversely, in our study, the effect of the prostaglandin analog on VEGF expression in RSMC is comparable to that of forskolin, suggesting that only the CAMP pathway is involved in this regulation.

In vascular smooth muscle cells, we show that adenosine treatment caused small changes in intracellular CAMP concentration; however, this response was greatly potentiated by the presence of the phosphodiesterase inhibitor IBMX. Similar observations were made in porcine aortic smooth muscle cells, where the enhancement of intracellular CAMP levels following forskolin treatment are also potentiated by phosphodiesterase inhibitors [24]. Intracellular levels of CAMP ap- 
pear to be tightly regulated by phosphodiesterase activities in RSMC. Moreover, our results are consistent with previous observations reporting a dose-dependent increase of CAMP in cultured rabbit intestinal smooth muscle cells by adenosine [15].

These changes in CAMP production might be mediated via the adenosine receptor $A_{2}$, present in vascular smooth muscle cells and shown to be positively coupled to adenylate cyclase [15]. In addition, adenosine stimulates VEGF mRNA expression in RSMC. Interestingly, this positive effect of adenosine on CAMP levels correlates with the enhancement of VEGF mRNA expression in these cells and argues that changes in CAMP in intracellular compartments are sufficient to directly control the upregulation of VEGF mRNA expression. Our results thus support our initial hypothesis that adenosine may participate to the metabolic control of angiogenesis.

Since adenosine production has been shown to increase under hypoxic conditions [25], the enhancement of CAMP by adenosine may contribute to upregulate VEGF mRNA expression in RSMC in physiopathological situations.

Finally, we found that VEGF expression is augmented in an additive manner by adenosine and cobalt. The effect of hypoxia on transcriptional activation of VEGF is well documented. Recently, I keda et al. [11] observed a fast induction of transcriptional activation during hypoxia and a slower increase in VEGF mRNA stability in glioma cells. The respective roles of adenosine on transcription or VEGF mRNA stability remain to be elucidated.

In conclusion, our studies have shown that RSMC and RAF express VEGF mRNA, suggesting a paracrine effect of VEGF in the vascular wall. In RSMC, this expression appeared to be upregulated by different agents that increase intracellular CAMP. The CAMPdependent effect appeared to interact positively with hypoxia. Our results also illustrate a cell-specific role of CAMP in vascular cells. High levels of CAMP did not affect VEGF expression in RAEC, but directly inhibited endothelial cell proliferation [26]. On the other hand, high levels of CAMP stimulated the expression of VEGF in RSMC. This RSMC-derived VEGF could control endothelial cell growth and regrowth.

We thank Dr. A. Ladoux for providing the CDNA of rat VEGF 164 . This work was supported by a grant from the Fondation de France. M.E.P. was supported by the Assistance Publique- Hôpitaux de Paris and G.D. was supported by the Société de Secours des Amis des Sciences.

Received August 13, 1997

\section{REFERENCES}

1. Leung, D. W., Cachianes, G., Kuang, W. J ., Goeddel, D. W., and Ferrara, N. (1989) Science 146, 1306- 1309.

2. Ferrara, N., Houck, K., J akeman, L., and Leung, D. W. (1992) Endocrine Rev. 13, 18- 32.

3. Quinn, T. P., Peters, K. G., De Vries, C., Ferrara, N., and Williams, L. T. (1993) Proc. Natl. Acad. Sci. USA 90, 7533- 7537.

4. J akeman, L. B., Winer, J ., Bennett, G. L., Altar, C. A., and Ferrara, N. (1992) J. Clin. Invest. 89, 244- 253.

5. Shibuya, M. (1995) Adv. Cancer Res. 67, 281- 316.

6. Tischer, E., Mitchell, R., Hartman, T., Silva, M., Gospodarowicz, D., Fiddes, J . C., and Abraham, J . A. (1991) J . Biol. Chem. 266, 11947- 11954.

7. Claffey, K. P., Wilkison, W. O., and Spiegelman, B. M. (1992) J . Biol. Chem. 267, 16317-16322.

8. Shweiki, D., Neeman, M., Itin, A., and Keshet, E. (1995) Proc. Natl. Acad. Sci. USA 92, 768- 772.

9. Goldberg, M. A., and Schneider, T. J . (1994) J . Biol. Chem. 269, 4355- 4359.

10. Levy, A. P., Levy, N. S., Wegner, S., and Goldberg, M. A. (1995) J . Biol. Chem. 270, 13333-13340.

11. Ikeda, E., Achen, M. G., Breier, G., and Risau, W. (1995) J . Biol . Chem. 270, 19761- 19766.

12. Hori, M., and Kitakaze, M. (1991) Hypertension 18, 565- 574.

13. Bellardinelli, L. (1993) Drug Dev. Res. 28, 263- 267.

14. Meininger, C.J ., Schelling, M.E., and Granger, H.J. (1988) Am. J. Physiol. 255, H554-H562.

15. Murthy, K. S., and Makhlouf, G. M. (1995) Mol. Pharmacol . 47, 1172- 1179.

16. Li, J ., Perrella, M. A., Tsai, J . C., Yet, S. F., Hsieh, C. M., Yoshizumi, M., Patterson, C., Endege, W. O., Zhou, F., and Lee, M. E. (1995) J . Biol. Chem. 270, 308- 312.

17. Stavri, G. T., Hong, Y., Zachary, I. C., Breier, G., Baskerville, P. A., Yla-Herttuala, S., Risau, W., Martin, J . F., and Erusalimsky, J . D. (1995) FEBS Lett. 358, 311- 315.

18. Ladoux, A., and Frelin, C. (1993) Biochem. Biophys. Res. Commun. 194, 799-803.

19. Battle, T., Arnal, J .F., Challah, M., and Michel, J. B. (1994) Tissue Cell 26, 943- 955.

20. Duijvestijn, A. M., Van Goor, H., Klatter, F., Majoor, G., Van Bussel, E., and Van Breda Vriesman, P. J . C. (1992) Lab. Invest. 66, 459- 466.

21. Fischer, S., Sharma, H. S., Karliczek, G. F., and Schaper, W. (1995) Mol. Brain Res. 28, 141- 148.

22. Hashimoto, E., Kage, K., Ogita, T., Nakaoka, T., Matsuoka, R., and Kira, Y. (1994) Biochem. Biophys. Res. Commun. 204, 318324.

23. Harada, S., Nagy, J . A., Sullivan, K. A., Thomas, K. A., Endo, N., Rodan, G. A., and Rodan, S. B. (1994) J . Clin. Invest. 93, 2490- 2496.

24. Souness, J . E., Hassal, G. A., and Parrot, D. P. (1992) Biochem. Pharmacol. 44, 857-866.

25. Belardinelli, L., Linden, J., and Berne, R. M. (1989) Prog. Cardiovasc. Dis. 32, 73-97.

26. D'Angelo, G., Lee, H., and Weiner, R. I. (1997) J . Cell. Biochem. 67, 353-366. 